\title{
Distinctiveness in short-term memory
}

\author{
DOUGLAS K. DETTERMAN* and NORMAN R. ELLIS \\ University of Alabama, University, Ala. 35486
}

Six experiments yielding serial position data using a positional probe task were compared to predictions made on the basis of distinctiveness. The concept of distinctiveness is derived from psychophysical theory and indicates the degree to which a particular stimulus in a group "stands out" from the other stimuli in that group. It was found that the obtained results agreed closely with those predicted. The results were suggested as a possible explanation for the bowed serial position effect in short-term memory.

An adequate explanation of the asymmetrical bowed shape of the serial position curve deriving from studies of learning and memory has not been forthcoming after decades of study. The importance of this issue has been reemphasized by the plethora of recent research and theory in short-term memory. Indeed, some general theories of memory are based on the shape of the curve. In any single serially presented list, there are two informational components ordinal position and the stimulus item appearing in that position. Attempts at predicting the shape of the serial position curve have most often focused on properties of the stimulus items and their interactions with other items in the list, to the neglect of ordinal position.

Murdock (1960) has attempted to explain the effect solely on the basis of ordinal position, viewed as a "distinctive cue." $\mathrm{He}$ reasoned that correct responses would be distributed over serial positions on the basis of distinctiveness of the stimuli, defined as the ease with which they are discriminated from other stimuli or the extent to which they "stand out." Basing his position on conventional psychophysical analyses, he assumed that equal psychological distances between stimuli were represented by the $\log _{10}$ of their physical intensities. With this assumption, it was possible to compute the distinctiveness of each stimulus in a group by comparing it to every other. Such comparisons yield a value designated as distinctiveness (D). Summing the D values for all stimuli in the group yields total distinctiveness (TD). Percentage $\mathrm{D}(\mathrm{D} \%)$ is given by $\mathrm{D} / \mathrm{TD}$. The proportion of correct responses made to a particular stimulus is reflected in $\mathrm{D} \%$,

While Murdock presents two schemes for computing $\mathrm{D} \%$, the easier would seem to be to conceive of an $\mathrm{n}$ by $\mathrm{n}$ matrix of simultaneous equations, where $n$ equals the number

* Requests for reprints should be sent to the first author, who is presently in the Psychology Department of the University of Davton, Dayton, Ohio 45409. of stimulus terms. For a list of four stimulus items, the matrix would be:

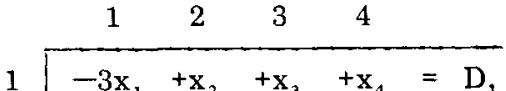

$$
\begin{aligned}
& 1-3 x_{1}+x_{2}+x_{3}+x_{4}=D_{2} \\
& 2-\mathrm{x}_{1}-\mathrm{x}_{2}+\mathrm{x}_{3}+\mathrm{x}_{4}=\mathrm{D}_{2} \\
& 3-\mathrm{x}_{1}-\mathrm{x}_{2}+\mathrm{x}_{3}+\mathrm{x}_{4}=\mathrm{D}_{3} \\
& 4-\mathrm{x}_{1}-\mathrm{x}_{2}-\mathrm{x}_{3}+3 \mathrm{x}_{4}=\mathrm{D}_{4} \\
& \Sigma D=T D
\end{aligned}
$$

Then, $\mathrm{D}_{1} \%=\mathrm{D}_{1} / \mathrm{TD}, \mathrm{D}_{2} \%=\mathrm{D}_{2} / \mathrm{TD}$, etc. In the above matrix, subscripts represent the order by magnitude of each stimulus in the group. Thus, $x_{1}$ is the smallest stimulus and $x_{4}$ the largest. Coefficients of the terms composing the principal diagonal are computed by the formula $[n-(2 i+1)]$, where $n$ is the number of items in the group and $i$ is the ordinal position in the group of the $i^{\text {th }}$ item. These coefficients form a progression by 2 s from $-(n-1)$ to $(n-1)$. All terms to the left of the principal diagonal are negative and all terms to the right positive. By substituting the $\log _{10}$ value of the stimulus intensity for the corresponding terms in each of the equations, it is an easy matter to compute all $D_{i}$.

In his original formulation, Murdock was successful in applying this analysis to data from diverse sources. One of the experiments dealt with serially learned lists, and he was able to predict rather precisely the resulting serial position curves. However, in a recent investigation of short-term memory, he was unsuccessful (Murdock, 1968).

The present research presents further tests of Murdock's notion with data from short-term memory experiments. Two changes are made in his procedure. First, it was noted that the assignment of Ordinal Position 1 to the first item presented was arbitrary. A "physical intensity" of 1 could have as well been assigned to the last item, and in the present data this was done.
The serial learning data used by Murdock also derived from a different experimental model. In his procedure, a list of items was presented visually, the $E$ verbally indicated a serial position, and the $S$ attempted to recall the stimulus item in that position. In the technique used here, and described by Murdock as a "positional probe technique," the list was presented visually, a stimulus item which had appeared in the list was then presented visually, and the $S$ was required to indicate the spatial serial position in which this item had appeared.

\section{METHOD}

All of the experiments are of the probe-recall type (Ellis, 1970), and in no instance were they executed with the intention of testing Murdock's predictions. Each of the experiments is reported in greater detail elsewhere (Anders, 1968, Experiments IV and V; Ellis, 1970, Experiment VI; Ellis, 1969, Experiment III; Ellis \& Dugas, 1969, Experiment II; Ellis \& Hope, 1968, Experiment I), and only a brief description of the general methodology employed will be presented.

\section{Subjects and Procedure}

The apparatus was an oblong box with a row of miniature projectors mounted on the lower third of the sloping front face. Stimulus items, numbers and letters, depending on the experiment, were presented sequentially in the projectors from left to right. After each projector had presented a different item, a probe projector, mounted above and in the middle of the row, re-presented one of the stimuli. The S's task was to remember where the stimulus appeared. He was to press a clear Plexiglas response key mounted over the projector, and if the item had appeared in that position a door chime would sound. A correction procedure was used.

Series of stimuli were counterbalanced in each experiment so that every item appeared equally often in every position and so that each item and each position were tested for recall equally often. The item exposure in these experiments varied from 1.0 to $1.5 \mathrm{sec}$. Recall was immediate.

Before testing, Ss were given instructions and then a few practice trials. If the number of trials required to complete an experiment exceeded the S's tolerance, several sessions were given, but each $S$ was treated equally within an experiment. Each serial position was probed from 4 to 10 times for recall, depending on the experiment. During testing, the $E$ sat behind the $S$, operating the apparatus and recording all responses. 

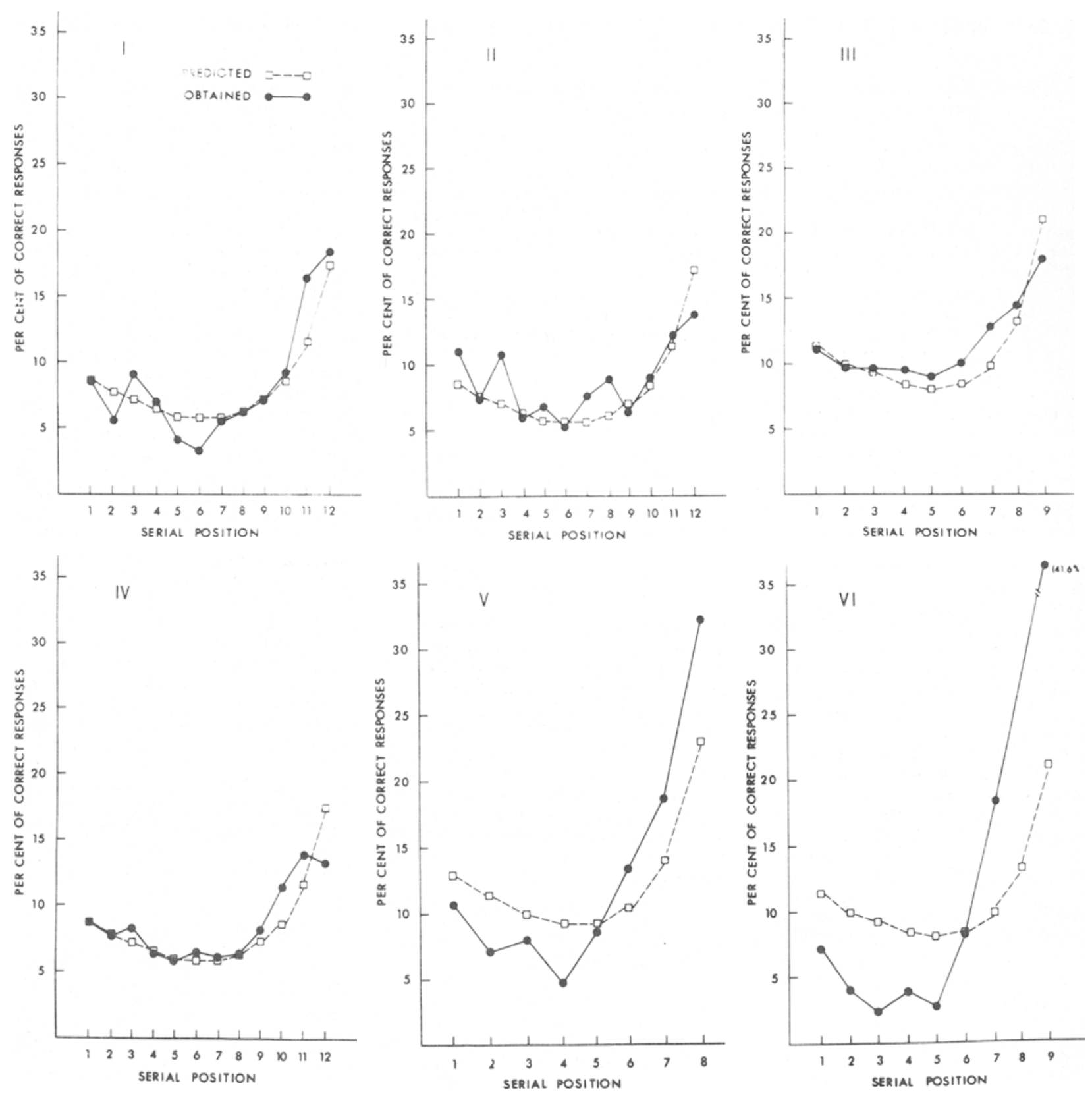

Fig. 1. A comparison of obtained and predicted results.

RESULTS AND DISCUSSION

The analyses followed the procedure outlined earlier. The percent of total correct first-choice responses was calculated for each position for each $\mathrm{S}$. These values were then averaged over Ss and compared to the predicted results. These are presented in Table 1 and graphically in Fig. 1. The standard error of estimate is also provided. It should be noted that while analyses were conducted, assigning a value of 1 to the last serial position, the data are presented graphically in the more traditional manner of referring to the first position presented as Position 1. The predictions are surprisingly accurate. Two experiments (Experiments $\mathrm{V}$ and VI) employed retardates, and their data deviated most from the expected values. In both experiments, the differences found followed the same pattern-more correct responses were made to later serial positions and fewer to earlier positions than predicted. A number of other studies of retardates in this laboratory have yielded similar results (Ellis, 1969).
These findings have led to a hypothesis that retardates' rehearsal strategies are defective, and, therefore, they fail to transfer information from primary to secondary memory (as defined by Waugh \& Norman, 1965). It may be possible to reconcile this explanation with Murdock's notion of cue distinctiveness by asserting that cue distinctiveness is a necessary condition for rehearsal. Therefore, either ordinal position as a cue could be less distinct for the retardate, thus attenuating rehearsal, or the traces of these cues may fade more rapidly in these Ss, as 
Table 1

The Difference (Diff) Between Obtained and Predicted Results and the Standard Error of Estimate (SEE) for Each Serial Position of Each Experiment

\begin{tabular}{|c|c|c|c|c|c|c|c|c|c|c|c|c|}
\hline \multirow{3}{*}{$\begin{array}{c}\text { Serial } \\
\text { Position }\end{array}$} & \multicolumn{12}{|c|}{ Experiment } \\
\hline & \multicolumn{2}{|c|}{ I } & \multicolumn{2}{|c|}{ II } & \multicolumn{2}{|c|}{ III } & \multicolumn{2}{|c|}{ IV } & \multicolumn{2}{|c|}{$\mathrm{V}$} & \multicolumn{2}{|c|}{$\mathrm{VI}$} \\
\hline & Diff & SEE & Diff & SEE & Diff & SEE & Diff & SEE & Diff & SEE & Diff & SEE \\
\hline 1 & -0.19 & 4.84 & 2.45 & 3.91 & -0.46 & 3.77 & -0.04 & 5.39 & -2.07 & 7.85 & -4.27 & 11.70 \\
\hline 2 & -2.49 & 5.45 & -0.76 & 4.17 & -0.41 & 3.96 & -0.41 & 3.48 & -4.20 & 8.01 & -6.05 & 7.96 \\
\hline 3 & 2.01 & 5.84 & 3.75 & 5.09 & 0.51 & 4.04 & 1.19 & 4.53 & -1.92 & 6.33 & -6.95 & 8.49 \\
\hline 4 & 0.42 & 4.82 & -0.57 & 3.10 & 1.26 & 3.63 & -0.19 & 4.14 & -4.53 & 6.79 & -4.43 & 7.35 \\
\hline 5 & --2.31 & 4.40 & 0.77 & 3.48 & 0.97 & 3.31 & -0.35 & 3.97 & -2.26 & 5.90 & -5.38 & 7.31 \\
\hline 6 & -2.94 & 4.77 & -0.82 & 3.16 & 1.76 & 3.52 & 0.47 & 4.32 & 2.89 & 8.85 & -0.09 & 8.55 \\
\hline 7 & -0.60 & 5.46 & 1.81 & 3.75 & 3.07 & 5.09 & 0.18 & 3.80 & 4.52 & 9.20 & 1.55 & 10.64 \\
\hline 8 & -0.13 & 5.79 & 2.75 & 4.23 & 1.20 & 4.20 & 0.12 & 4.63 & 9.33 & 14.58 & 5.27 & 13.46 \\
\hline 9 & -0.27 & 5.96 & -0.76 & 3.72 & -5.05 & 6.41 & 1.09 & 4.67 & & & 20.25 & 24.92 \\
\hline 10 & 0.64 & 5.52 & 0.71 & 3.83 & & & 2.90 & 5.73 & & & & \\
\hline 11 & 4.86 & 8.77 & 0.88 & 4.11 & & & 2.47 & 4.72 & & & & \\
\hline 12 & 1.09 & 9.16 & -3.91 & 6.16 & & & -4.21 & 7.05 & & & & \\
\hline
\end{tabular}

Ellis (1963) has postulated.

Why does the "distinctiveness function" fit Murdock's original serial learning data and our results on short-term memory, but not those of Murdock? Why is it necessary to reverse the function in order to fit our data? We have no answer to these questions. Perhaps, as Tulving \& Madigan (1970) note, "The similarity of one 'serial position curve' to another, of course, is no guarantee that both are consequences of one and the same set of underlying processes [p. 454]."

It seems likely that distinctiveness of serial position may vary depending upon a number of variablespresentation rate, delay of recall, nature of stimuli, and even differences in sensory capacities among Ss (as may be the case with the mental retardate). It seems likely that our particular positional probe tasks would emphasize the role of order or position distinctiveness. Certainly, these results are predicted precisely. Though Murdock's distinctiveness function may not prove invariate, it would appear to be a useful construct.

\section{REFERENCES}

ANDERS, T. R. Short-term memory for serially presented supraspan information in normal and mentally retarded individuals. Unpublished doctoral dissertation, University of Alabama, 1965.

ELLIS, N. R. The stimulus trace and behavioral inadequacy. In N. R. Ellis (Ed.), Handbook of mental deficiency. New York: McGraw-Hill, 1963. Pp. 134-158.

ELLIS, N. R. Evidence for two storage processes in short-term memory. Journal of Experimental Psychology, 1969,80, 390-391.

ELLIS, N. R. Memory processes in retardates and normals. In N. R. Ellis (Ed.), International review of research in mental retardation. Vol. IV. New York: Academic Press, 1970. Pp. 1-32.

ELLIS, N. R., \& DUGAS, J. The serial position effect in short-term memory under $E-$ and S-spaced conditions. Psychonomic Science, 1968, 12, 55-56.

ELLIS, N. R., \& HOPE, R. Memory processes and the serial position curve. Journal of Experimental Psychology. $1968,77,613-619$.
MURDOCK, B. B., JR. The distinctiveness of stimuli. Psychological Review, 1960, 67, 16-31.

MURDOCK, B. B., JR. Serial order effects in short-term memory. Journal of Experimental Psychology, 1968, 76 (Monograph Supplement, No. 4, Part 2).
TULVING, A., \& MADIGAN, S. A. Memory and verbal learning. In $P$. Mussen and $M$ Rosenzweig (Eds.), Annual review of psychology. Vol. 21. Palo Alto, Calif: Annual Reviews, 1970 Pp. 437-484.

WAUGH, N. C., \& NORMAN, D. A. Primary memory. Psychological Review, 1965, 72 , 89-104.

\title{
Semantic and acoustic labeling*
}

\author{
DOUGLAS CARROLL and PETER V. HORNE \\ Australian National University, Canberra, A.C.T., Australia
}

Two experiments demonstrate that both semantic and acoustic labels enhance memory. Such data is in disaccord with theories that attempt to dichotomize memory in terms of differential semantic and acoustic encoding.

Dale \& McGlaughlin (1970) showed that memory for surnames can be enhanced by using semantic labels. Acoustic labels, on the other hand, were ineffective. This can be explained by assuming a rapid decay of the acoustic trace in memory and would support a long-term memory (LTM)/short-term memory (STM) dichotomy on the basis of different coding systems, i.e., semantic coding being characteristic of LTM and acoustic coding of STM (Baddeley, 1966a, b; Baddeley \& Dale, 1966). Some studies, however, have shown semantic influence in STM (Wickens \& Simpson, 1968; Wickens \& Eckler, 1968), and acoustic coding in LTM (Gruneberg \& Sykes, 1969).

Two experiments evaluate an alternative explanation of Dale and McGlaughlin's results. Their acoustic labels were towns and their semantic labels, occupations. This suggests differential retrieval of the two types of label, perhaps based on varying degrees of concreteness (Paivio, 1969). The first experiment replicates Dale and McGlaughlin's study, with an additional condition in which Ss have the labels available during recall. In the second experiment both acoustic and semantic labels are occupations. The two experiments, then, compare the effects of semantic and acoustic labels when both are equally available.

\section{METHOD}

\section{Experiment}

Ss were 40 students enrolled in an introductory course in psychology. The task was free recall. The material to be remembered was a list of 40 surnames, 20 having semantic labels (Mr. Law, the policeman) and 20 having acoustic labels (Mr. Worth, of 